\title{
"El último vagón": sexualidad, cuerpo y espacio. Una aproximación a las prácticas homoeróticas entre hombres en el metro de la Ciudad de México
}

\author{
José Octavio Hernández Sancén \\ Universidad Pablo de Olavide, España-México \\ oct.sancen@gmail.com
}

\section{Resumen}

El presente artículo pretende generar una reflexión en torno a las prácticas homoeróticas entre hombres en el "último vagón" del metro de la Ciudad de México. Se propone describir y comprender el proceso de apropiación del espacio y la construcción de los pactos de complicidad entre los usuarios-hombres. En este trabajo, el "último vagón" del metro se vislumbra como un espacio colectivo de significaciones sociales en torno a la sexualidad y el cuerpo, las prácticas homoeróticas y su diversidad.

Palabras clave: “último vagón”, sexualidad, cuerpo, prácticas homoeróticas, subjetividad. 


\title{
"The last subway car": sexuality, body and space. An approach to homoerotic practices among men in the subway of Mexico City
}

\begin{abstract}
This article aims to generate a reflection on homoerotic practices among men in the "last car" of the Mexico City subway. It is proposed to describe and understand the process of appropriation of space and the construction of complicity pacts between user-men. In this work, the "last subway car" is seen as a collective space of social meanings around sexuality and body, homoerotic practices and diversity.
\end{abstract}

Keywords: "last subway car", sexuality, body, homoerotic practices, subjectivity.

Fecha de recepción: 25 de octubre de 2019.

Fecha de aprobación: 21 de marzo de 2020. 
Amar es este tímido silencio cerca de ti, sin que lo sepas, y recordar tu voz cuando te marchas y sentir el calor de tu saludo.

"Amor"

(Fragmento de poema) Salvador Novo, Espejo (1933).

\section{Palabras preliminares}

Algunos trabajos entre muchos tantos (Novo, 1998; Núñez, 1994 [2000]; Carrillo, 2002; Gallego, 2010; Laguarda, 2010; Monsiváis, 2010; Vendrell, 2013; Núñez, 2017) han apostado por el estudio de los hombres en el tema de la diversidad sexual, el homoerotismo y el uso de los placeres en los procesos de apropiación del espacio público en México. En ellos se destaca que ha sido de manera progresiva a través del uso y significado que confieren a los mismos. En la actualidad los hombres que mantienen prácticas homoeróticas con otros hombres se han apropiado del espacio público con una variabilidad operable, hasta cierto punto, ya que la heterogeneidad de los mismos es significativa y los horarios en que se dan cita se yuxtaponen con los itinerarios de vida cotidiana.

En este sentido y para este trabajo, resulta enriquecedor abordar el estudio de las prácticas homoeróticas entre hombres en el espacio público del metro de la Ciudad de México, fundamentalmente a partir de las corporalidades que lo significan y visibilizan como un fenómeno sociocultural que surge de las llamadas "minorías sexuales" en la megalópolis. El contexto urbano, el anonimato, el "secreto a voces", la exclusión y marginación con la que se viven estas prácticas, vislumbran la complejidad de su condición.

Para analizar la significación de estas prácticas se recurrió a la etnografía, como metodología primordial, y a las entrevistas informales desarrolladas en el transcurso de la observación participante. Las observaciones fueron sistemáticamente anotadas en el diario de campo y a la vez, la herramienta fundamental de trabajo. La aproximación al terreno se hizo de forma gradual en la última década del siglo pasado y durante los desplazamientos a la universidad, principalmente, aunque también la entrada al campo podía estar supeditada a los emergentes de la 
vida cotidiana. Durante los trayectos se observaron determinados encuentros que pusieron en evidencia que el contexto del metro era un lugar de interacciones para muchas personas, pero en especial para hombres que aprovechaban el viaje para establecer formas de contacto versátiles, incluso de tipo erótico y sexual. La pregunta por la significación de estas interacciones condicionó focalizar y afinar la mirada, ya no como un transeúnte más, sino como investigador. De esta manera la aproximación al metro fue gradual y con base en las especificidades de cada uno de sus espacios, especialmente en el "último vagón". Estando allí, fue posible constatar cómo juega el encuentro corporal y la sexualidad entre aquellos hombres que asumen una identidad homosexual y/o gay, pero también entre aquellos que no se adscriben a la misma pero que, de manera proactiva, sostienen el contacto homoerótico con otros hombres.

El metro, en especial el "último vagón", es un contexto de extraordinaria complejidad que pone en evidencia el poder de la subjetividad y su potencia creadora y transformativa a través del vínculo que estable el sujeto con el espacio. En estos procesos, se confirma que el cuerpo, además de ser carne, "puede adquirir una dimensión simbólica propia y convertirse en un elemento clave en la acción comunicativa" y también "agente de intersección de orden individual, psicológico y social" (Langarita, 2015:128) que remite (a través de las prácticas) a un conjunto de preceptos y lógicas producto de largos y complejos procesos socioculturales.

En este sentido, a medida que los espacios se van definiendo, también las prácticas se van especializando. En el caso del "último vagón" del metro, a partir de denominaciones locales que remiten a una serie de acciones definidas bajo el verbo "metrear", se construyen nuevas acciones que en último término implican también una identidad ("las metreras"), que no es compartida por igual por todos aquellos que participan de este tipo de intercambios sexuales. Los lugares y espacios sociales son diversos y muy amplios, forman parte estructural de la subjetividad y dan cuenta de las múltiples producciones del imaginario social porque "operan como organizadores, dan cuerpo a las creencias colectivas de un grupo social, una cultura, etcétera, permitiendo el anclaje de los seres humanos a través de la estructuración de sus subjetividades en los largos y lentos procesos históricos" (Fernández, 1993:164). En el caso que se menciona, estas múltiples producciones del imaginario social perfilan los encuentros entre hombres bajo una lógica homoerótica que se expresa a través de sus prácticas y el entorno que subjetivan. 
Desde aquí se puede inferir que en el devenir histórico los grupos de hombres con prácticas homoeróticas en la Ciudad de México han creado todo un lenguaje de intercambio y códigos de comunicación que les facilita la apropiación de los espacios públicos urbanos, intentando colocar lo marginal en el centro en el que se visibiliza e invisibiliza de forma simultánea su sexualidad. Este hecho tiene una doble significación, por un lado, tiene un carácter subversivo, en cuanto al particular proceso de apropiación de los espacios, pensados para dinámicas ordinarias y utilitarias que se contraponen con el uso que estos hombres protagonizan, pero, por otro lado, contribuyen a mantener el orden social establecido que da pauta al juego entre la realidad heternormativa y las interacciones entre hombres.

Es por esto que, el fenómeno de las prácticas homoeróticas en el "último vagón" del metro, es relevante y pertinente, porque el metro es el transporte público por excelencia, el más característico y emblemático en la cultura urbana mexicana. Pieza clave para comprender el significado de las dinámicas sociales y las prácticas corporales disidentes situadas en la frontera entre lo público y lo privado. En las próximas páginas y partiendo de una visión relacional de la corporalidad, que pone de manifiesto la necesidad de analizar la imbricación entre cuerpo, subjetividad y contexto, se abordará la apropiación del "espacio metrero" y la interacción entre los cuerpos de quienes son sus sujetos.

\section{El metro: en los bordes de la sexualidad}

Al andar la ciudad y vivir el metro es inevitable no sentirse confrontado por la vida cotidiana de sus habitantes. A cada instante surge un campo de problemas por indagar. La red multicolor adquiere la forma de un rizoma (Deleuze y Guattari, 2000), amplio y conectado al dinamismo de la ciudad con los transportes colectivos y sus diversos usos (laborales, académicos, personales, de ocio y turismo), o con otros lugares (entre avenidas, calles, callejones, parques, plazas y museos) donde las relaciones humanas fluyen entre sus vagones, andenes y pasillos.

¿Cómo pensar a la Ciudad de México sin la vida cotidiana en el metro? Es posible que dicha pregunta sea impensable porque se entiende al metro como un eje articulador para la movilidad de las grandes masas, columna vertebral de la megalópolis y transporte colectivo donde se viven grandes momentos de la vida urbana. Hablar del metro es pensar en el tiempo y en sus "horas 
pico", las más concurridas, las más buscadas y necesarias donde "el apretujón" derrama la esencia de quienes viajan en sus vagones (Monsiváis, 2009). El espacio colectivo y heterotópico de las diversidades humanas desbordadas, donde se "expresa la vida misma de la gran ciudad": intensidades de aromas, ecos de palabras, miradas fugaces y efímeras, contactos múltiples entre cuerpos flácidos y torneados, todo bajo la musicalidad del "tururú" de su máquina al ritmo del desplazamiento del convoy. Al transitar por sus rutas, en ciertas condiciones temporales y espaciales, el sentido del metro ya no solo es el de un medio de transporte, sino que se le da un giro distinto y alternativo, al ser apropiado por ciertas prácticas que, dejando huellas, advierten de sus otros usos, donde la sexualidad es la principal protagonista.

La imagen de un condón tirado en el piso al abrirse las puertas del "último vagón”, por primera vez reveló, como real, aquellos encuentros entre hombres que se divulgaban en leyenda urbana a través de charlas con amigos y conocidos de ambiente ${ }^{2}$.

¿Es posible pensar que la "cualidad" del metro para ser un espacio colectivo, de tránsito, heterogéneo y diverso, facilita el despliegue de encuentros homoeróticos entre hombres a través del anonimato? Si así fuera, ¿qué producciones de subjetividad y modos de relación existen en el encuentro entre el espacio del "último vagón" y los hombres que hacen uso del mismo?, ¿qué significados adquiere para ellos el viaje en este tipo de transporte? El interés por indagar, conocer y saber qué es lo que acontece en su interior dieron pauta a este proceso de investigación en devenir.

El "último vagón" del metro es un espacio que parte del claroscuro de los "tabús" de la sexualidad en México. Una realidad que asciende desde lo ominoso y perverso del ser humano. Un tema que plantea diversas cuestiones desde su negación y prohibición, pero al mismo tiempo

\footnotetext{
${ }^{1}$ Las "horas pico" pueden ser definidas desde dos polos, siempre en extremos y haciendo referencia al tiempo y al lugar. El primero, vinculado al horario donde un grupo de personas se reúnen en un sitio específico y a determinada hora en el que coinciden para realizar el recorrido por la gran ciudad dependiendo de los itinerarios de cada usuario y/o los objetivos del viaje. El segundo, que se refiere al tiempo y el lugar que suele estar desocupado o menos concurrido por las personas al realizar el viaje por la ciudad o transitar por el metro.

${ }^{2}$ El ambiente es el conjunto de elementos que integran el espacio de "lo gay". Alude a una "subcultura homosexual" que abre la posibilidad para reflexionar sobre la multiplicidad de construcciones sociales en torno a la diversidad. El "ambiente", nos sugiere Laguarda (2010), hace referencia a un círculo de personas que comparten "algo en común" y que no está disponible para todos. En el "ambiente" están incluidos esos espacios de socialización y sociabilidad en la ciudad y que en muchos casos posibilitan las relaciones homoeróticas, de amistad, noviazgo, "ligue", "faje", "metreo".
} 
diversas lecturas desde lo enigmático de sus orígenes para quienes viven y transitan por esta ciudad al estar vinculado a las diversas aristas de grupos que han sido históricamente vulnerados por y desde su diversidad y disidencia sexual ${ }^{3}$.

El "último vagón" es parte de un transporte público, pero desde sus viajes emergen momentos para el "ligue", "la amistad" y "el sexo" con la creencia (en algunos casos) de que allí es posible encontrar el "amor" entre los viajeros hombres que se arriesgan a buscarlo.

[...] es como una pretensión de tener cierta seguridad de que en este lugar voy a encontrar, de que voy a conocer a una persona homosexual. No necesariamente el amor de mi vida, pero puedo conocerlo... A lo mejor dices, buscando el amor de mi vida, pero busco el sexo, a lo mejor puede ser que digas, busco sexo, pero en realidad lo que no buscas es solamente sexo, buscas algo más [...] para suplir, decía yo, ciertos vacíos que tienes [...] falta de afecto por parte de la familia, en algunos casos de parejas [...] porque el cariño que buscan en esa persona no lo tienen [...] (Luis).

El "putivagón" también llamado "vagón feliz", es un espacio heterotópico no solo para el comercio, el descanso, la seguridad y la restricción (por mencionar algunos usos) sino también espacio de identificación y resguardo para quienes se viven con el sentido de pertenencia a grupos de la diversidad sexual o todo lo contrario, para quienes no se asumen desde las identidades estigmatizadas (homosexual y/o gay) pero que en el anonimato sostienen prácticas de placer que involucran el acto de la seducción a través del "ligue" y el "metreo".

[...] cuando lo comprobé hubo una parte de mí que se identificó en muchos sentidos. ¿Por qué? Porque hablamos de cierto grupo, que es un grupo con cierta tendencia sexual y se tiene identificación con ellos porque dentro del vagón tú puedes ser más libre, si es que te sientes incómodo con la demás gente por ciertas cosas que tenemos como gays, como el caminar, el hablar, el sentarte. Creo que entre nosotros es una manera de estar en sintonía y de que te

\footnotetext{
${ }^{3}$ Es importante aclarar que en este trabajo se reconoce a la sexualidad como constructo social, aludiendo a las fuerzas sociales que la configuran (Weeks, 2000) y que es posible estudiarla a través de las prácticas sociales que le dan forma y organización; una representación de la sexualidad que permite visibilizarla. En otras palabras, es "un resultado de distintas prácticas sociales que dan significado a las actividades humanas, de definiciones sociales y autodefiniciones, de luchas entre quienes tienen el poder para definir y reglamentar contra quienes se resisten" (Weeks, 2000:30).

${ }^{4}$ El "metreo" es un término de uso general entre el lenguaje "defeño" (de la capital), no exclusivo de algún grupo identitario, minoritario o no, al contrario, es un término que se usa hasta coloquialmente entre quienes habitan en la gran ciudad o más allá de sus márgenes. Se usa para referirse a la acción que llevan a cabo las "metreras" para sostener prácticas homoeróticas con otros hombres en los contextos del metro y del "último vagón". Las "metreras", quienes son portadoras de esta nueva identidad urbano-local, son hombres que viajan por el metro exclusivamente con el objetivo de ligar, seducir, cortejar, tener algún tipo de encuentro homoerótico con otros hombres (usuarios del metro y desconocidos). Las "metreras" no tiene otro fin más que el de recibir y dar placer por el placer. Por lo regular, viajan de una estación a otra, durante largas horas y por las diversas líneas de ruta de acuerdo a su itinerario personal buscando la oportunidad o el momento para la acción del "metreo".
} 
entiendes. Aparte me sentí cómodo por eso, ipor afinidad!, ipor pertenencia! Y me sentí cómodo porque ahí yo podía conocer a alguien como amigo y como ligue [...] Entonces, a mí me gusta ir a esos lugares (Raúl).

En el "último vagón" espacio y tiempo se imbrican para hacer, de las borrosas fronteras entre lo público y lo privado, nuevas realidades emergentes en constante devenir.

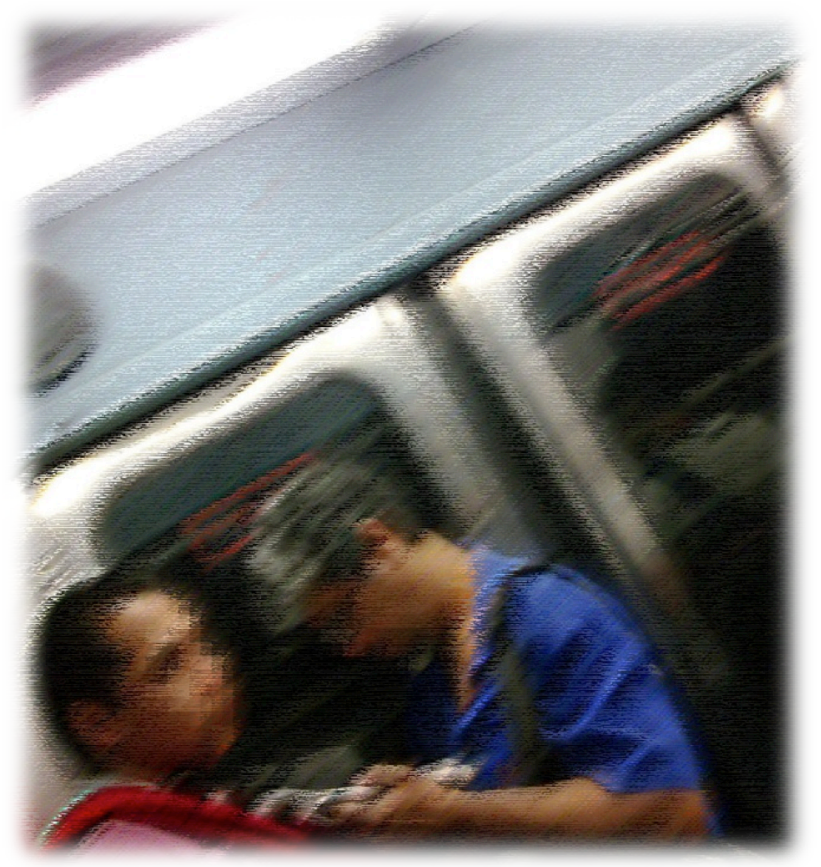

Foto 1. Simulación. Archivo personal, 2016.

\section{Lógica homoerótica: hacia el deseo, el cuerpo y el anonimato}

Es en el interior del "putivagón", al cierre de puertas, donde el tiempo se vincula con el movimiento. En el reducido o amplio espacio de su interior, la multitud encuentra en su cuerpo un potente instrumento para la expresión (a veces no tan libre) de su sexualidad. Los lenguajes verbales y no verbales, palabras secretas y frases entrecortadas, silencios y miradas furtivas combinadas con sensaciones piel a piel, hacen presencia con alocuciones que amplían la experiencia subjetiva. El cuerpo hecho de carne y humanidad, puede ser el principal instrumento vinculante, de mediación o conexión entre naturaleza y cultura. Es en el pliegue ${ }^{5}$ intersticial de

\footnotetext{
5 Al respecto de esta noción, Gilles Deleuze, comenta: "La materia orgánica, sin embargo, no es otra que la inorgánica [...] Inorgánica u orgánica, la materia es la misma, pero fuerzas activas que actúan sobre ella no son las mismas. Por supuesto, son fuerzas perfectamente materiales o mecánicas [...]” (1989:16).
} 
estos dos universos donde el cuerpo condensa su profundidad y la posibilidad del reconocimiento de la multiplicidad y, como sugiere Edgar Morin (2001), de la multidimensionalidad.

Pensar el cuerpo desde su singularidad, más allá de las certezas que establecen el orden de lo absoluto y el razonamiento de la ley, permite el reconocimiento de la sinrazón, los deseos, las pasiones, las necesidades, las creencias. El cuerpo es continuidad que trasciende binarismos esencialistas y sostiene sus desafíos. El cuerpo es "producto de la performatividad que está dada por los discursos que producen representaciones y las prácticas corporales cotidianas y ritualizadas que producen cuerpos dóciles, maleables y controlables" (Muñiz, 2010:46). Es decir, el cuerpo es cognoscible como complejidad a través de las prácticas como vía de acceso más allá de los polos cuerpo-mente.

Aludir a la complejidad del cuerpo, es aludir a la complejidad de las realidades que se habitan. Es una aproximación que sirve para comprender el mundo de lo social desde el reconocimiento de su entramado como el todo en sus partes y las partes en su todo. La relación entre cuerpo y espacio es productora de lugares y realidades implicadas en la cotidianidad de vagones, andenes y pasillos.

La experiencia, filtrada a través del trabajo etnográfico, dio la pauta para identificar cómo estos cuerpos se vincularon con la maquinaria del metro, en especial, aquellos cuerpos de hombres que se movían en el interior del "último vagón".

La armadura metálica del vagón se volvió parte o extensión del cuerpo, adquiriendo movimiento. Las puertas y ventanas, a través de su reflejo, facilitaron la interacción silenciosa con apoyo, siempre, de la mirada. Dichos elementos fueron utilizados por los usuarios-hombres como medios para apropiarse del lugar y hacerlo suyo.

La estructura metálica del interior de la máquina dio sostén al cuerpo. Se volvió (metafóricamente) una extensión del cuerpo, de tal manera que esto facilitó la aproximación al otro diferente y extraño. Sin embargo, conforme el metro avanzó en su trayectoria, las fronteras entre materia inerte y viva se desvanecieron.

Con base en lo anterior, resultó significativo lo compartido por estos hombres a través de su testimonio. El cuerpo adquirió para ellos un valor singular y vinculante, de poder y de resistencia, 
determinante de las prácticas homoeróticas y constitutivo del espacio como heterotopía (que resguarda la experiencia subjetiva) donde el deseo por el cuerpo y reconocimiento de la belleza exterior adquirieron profundos significados en las relaciones interpersonales.

La cara era demasiado viva... yo creo que es el compuesto de la cara, de lo que compone su cara, sus cejas, sus ojos, su cabello, el conjunto de su cara. Yo creo que después es como vayas vestido, los colores, la ropa, la combinación, etcétera. Lo bonito que puedas ser o lo atractivo que puedas ser aparte de todo (Christian).

Se reafirmó la complicidad como parte de una preferencia por el contacto con otro hombre: se van "agarrando y se dejan agarrar porque a fin de cuentas", señala un informante, "lo que recibes de un hombre jamás lo vas a recibir de una mujer".

[...] como te toque el trasero o como te toque la nalga, es diferente a como te lo va a tocar una mujer $[\ldots]$ a un hombre enséñale una y enseguida te la va a tocar, eso va a ser más que un imán [...] Un hombre heterosexual, lo que recibe ahí en el metro, nunca en su vida lo va a recibir de una mujer. La forma de tocar, así, casi con hambre, con desesperación, así salvaje [...] (Ricardo).

La cara y el pene fueron para ellos la tarjeta de presentación, partes del cuerpo que llamaron siempre su atención. Esto era evidente (a discreción), cada vez que se ingresaba al "último vagón". Se fijaba la mirada en el bulto resaltado, incluso antes de abordar el vagón. El pene ${ }^{6}$ fue la parte del cuerpo que motivaba los encuentros.

[...] la tarjeta de presentación sería como desde la cara. A lo mejor tienes ojos preciosísimos y eso te lleva a ser el centro de atracción o las cejas, y después hay una serie de cosas que son visuales y después te das cuenta, ya al tocar, que va con premio extra. Entonces, bueno, salí ganador [...] Entonces, como que sí hay un cierto nivel de excitación muy, muy leve, porque yo creo que los estas dominando y no son gay, ni son bisexuales, pero de alguna forma les han contado o equis, como que buscan, un tantito, ese contacto con hombres. Entonces no lo quitan, no se mueven. Uno tampoco se quita y al paso de las estaciones te vas dando cuenta que hay una respuesta $[\ldots]$ (Christian).

El silencio, como otro elemento transversal, fue utilizado para apropiarse del interior del vagón, se priorizó "el roce" de los cuerpos y apuntaló la interacción deseada y esperada hacia el encuentro con el otro. La complicidad del placer por el cuerpo, la solidaridad del secreto y la

\footnotetext{
${ }^{6}$ En este sentido es pertinente recordar que, desde tiempos ancestrales, manifiesto en sus imágenes, pero velado en sus discursos, el pene siempre ha sido la imagen representativa del falo; símbolo del poder y la masculinidad, no solo para el portador, sino también para quien resulta "ganador" o "vencedor" en la lucha cotidiana por el objeto anhelado.
} 
imaginación como fantasía, desplazaron el valor de la palabra (como elemento estructural de la comunicación humana) para crear un espacio de actos transgresores.

[...] hay gente que puede empezar a acercarse a ti y misteriosamente ya está su mano en la entrepierna o te está tocando el trasero o inclusive a lo que vas. O sea, te puedo decir que si no te empiezan a tocar es porque ya casi te bajan el cierre o la bragueta del pantalón, y si no es que te están acariciando, es porque ya te sacaron todo. Ya te sacaron los genitales (Raúl).

$[\ldots]$ entonces en silencio, nadie habla con nadie $[\ldots]$ además todos nos vamos rosando en todas partes y todo es tan de lado, que incluso puede ocurrir que vayas con las manos abajo [...] y de repente te encuentras con un bulto, con un pene, normal, flácido o semi-erecto [...] yo creo que, si buscan ser tocados, porque te dejan $[\ldots]$ pene contra mano, mano con el dorso (Luis).

Cada encuentro, desde la vivencia subjetiva de sus protagonistas, fue adquiriendo el sentido del ritual, en el que se compartieron saberes y prácticas colectivas entre quienes transitaron por la experiencia homoerótica, ya sea desde la apariencia del cuerpo y/o la interpretación que se hace de la imagen corporal como punto de identificación.

[...] Entonces yo vengo y en una de esas se me ocurre bajar la mano, y sí, un poco más la mano, y sí, un poco como para agarrar y acariciar la mano del otro chico; porque, de hecho, era un chico que traía el cabello pintado, traía ropa muy ajustada, cosas así que te indican: "bueno a lo mejor sí es" (Christian).

En el "último vagón" los encuentros homoeróticos entre hombres fueron parte de una negociación de contactos corporales, una socialización de cuerpos (socialicorporalidad), donde se implicaron los deseos estallando las fantasías a través de las diversas caricias por la piel, los besos húmedos, la estimulación de los pezones, el confort de los abrazos y los fetiches corporales. Con el cuerpo se resistieron ciertos roces, pero se aceptaron otros, los besos sí, pero no el contacto con las nalgas; la estimulación de los genitales sí, pero no los besos.

Lo que pasa en el metro es una forma de interactuar, de conocer gente con intereses afines [...] es una forma rápida y sencilla de conocer a alguien, de acercarte [...] de que te masturben o masturbes o [...] sexo oral o la penetración [...] En el metro, dentro del vagón, se establece una cierta complicidad, yo creo que entre todos los que están presentes porque se dan cuenta [...] Generalmente eliges el último vagón del metro porque es utilizado por muchos como una forma de conocer gente, quizás para lo que dura el trayecto, quizás para un prospecto a futuro [...] (Luis).

En la dinámica particular del "ligue", las nuevas tecnologías como los móviles, también tuvieron su función creadora; se volvieron un complemento para el cuerpo, para hacer más efectivos 
dichos encuentros. Esto es evidencia clara de que las prácticas homoeróticas también se han transformado, reubicadas y circunscritas a procesos sociales globalizados que sujetan las vidas de los hombres a itinerarios bajo una lógica de mercado con ciertas condiciones de ser y estar.

[...] Pero en ese momento, sí recibí cierta respuesta y favorable de alguna forma [...] me acarició y se me quedó viendo. Entonces, con un celular que tenía en aquel momento, con una pantalla grande, tecleé mi nombre y lo giré para que él lo viera y lo apuntó (Christian).

En estas prácticas, el anonimato fue otro elemento estructural, porque en él se encadenaron las miradas y se sostuvieron los silencios, el deseo y la negación. El anonimato que evoca a los "no lugares", permitió, a quienes lo utilizaron, la posibilidad de ser por sí mismos, sin juicio y prejuicio, sin aparente estigma por vivir su homoerotismo. En este sentido, el anonimato ofreció la posibilidad de existir sin identidad sexual para bordear lo "gay", lo "homosexual", lo "joto", lo "puto", lo "marica".

El "último vagón" es un lugar de tránsito para quienes se apropian de él. Es el medio de transporte que también adquiere el sentido de lugar antropológico ${ }^{8}$ (Auge, 2008) o de espacio practicado $^{9}$ (De Certeau, 2007), investido por la subjetividad, signado y reconocido por lo que representa para quienes son sus usuarios. El "putivagón" deviene en espacio para el encuentro erótico-sexual, posibilitando la emergencia de diversas formas de sociabilidad, innovada en socialicorporalidad, de las que unos pocos son protagonistas al entrar y salir en una constante producida por su implicación desde la experiencia y conocimiento de su existencia. Es allí donde la sexualidad puede ser expresada en los actos de transgresión que bordean los límites de la prohibición, siempre en tensión entre las fronteras de lo público y privado. El sujeto se apropia del espacio, lo hace suyo y desestabiliza la monotonía de sus certezas para inducir el

\footnotetext{
${ }^{7}$ Son espacios que no crean "ni identidad singular ni relación, sino soledad y similitud" (Augé, 2008:107). Espacios donde la historia no tiene lugar, donde se repiten las mismas imágenes y textos en una constante para hacer con el tiempo fragmentos de principio a fin. Espacios donde, quienes transitan a través de ellos, se "encuentran atrapados en los ecos y las imágenes de una suerte de cosmología objetivamente universal" (Ibíd::109).

${ }^{8}$ Según Marc Augé (2008), está cargado de sentido. Es el lugar donde "cada nuevo recorrido, cada reiteración ritual refuerza y confirma su necesidad [...] Se consideran (o los consideran) identificatorios, relacionales e históricos" (Augé, 2008:58).

9 Para Michel De Certeau (2007), es el espacio social o habitado. Es el resultado de un conflicto dialéctico permanente entre poder y resistencia social; con este término hace referencia al espacio como el producto de las operaciones que lo orientan, lo temporalizan, lo sitúan y lo hacen funcionar. Asimismo, en la visión protransformación social, De Certeau (2007) menciona que los consumidores se identifican con los ciudadanos, los que no pudiendo transformar directamente el espacio, lo adaptan a sus necesidades cotidianas, alternando sus normas y significados.
} 
desplazamiento de sentido que introduce otra lógica, alternativa, al tránsito y significado del viaje.

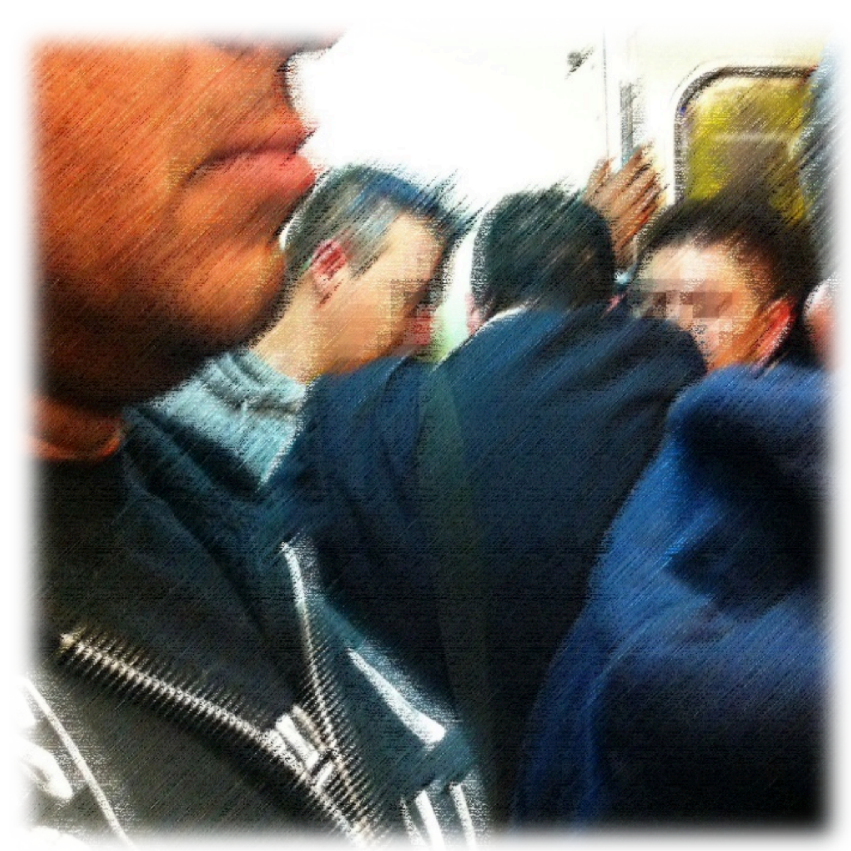

Foto 2. La casita. Archivo personal, 2016.

\section{La experiencia: lo cotidiano}

Siguiendo con la experiencia del trabajo de campo, se observó una variedad de comportamientos que se expresaron de manera diversa, comunicando deseos, sueños o expectativas de vida, matizados por la sexualidad y erotismo de los cuerpos; miradas y palabras que se mezclaron con y entre los hombres que viajaban en el "último vagón”.

Un hallazgo sustancial fue saber que todas las líneas tienen una estación, una puerta y un lugar específico para los encuentros. Por ejemplo, en el caso de la línea 3, de Indios Verdes a Universidad, fue en la última puerta del último y antepenúltimo vagón. De Universidad a Indios Verdes fue en la última puerta del "último vagón", y en el cuarto vagón, en la segunda puerta (solo durante el día). En la noche, entre las 22:30 y las 00:00 horas, fue (indiscutiblemente) en la última puerta del "último vagón”.

[...] En la noche sé que es el último vagón, es la regla de ese vagón (no universal) pero ese finalmente. En el último vagón, en la cola del tren, digamos, en las últimas dos puertas, es la zona 
para ligarse. Ahí van puros hombres exclusivamente, a lo mejor de las diez y media a las doce de la noche, que es la última corrida aproximadamente, en ese vagón van solamente hombres. A lo mejor se sube alguna pareja, pero más bien despistada, o alguna chava o algún chavo solos, pero también despistados. Son la minoría [...] En la noche, alguna vez por mera casualidad, pero sí es digno de notarse y de pensar, por qué van puros hombres, digo, van de diez a veinte hombres en los últimos asientos y se ve, un tanto, la carga sexual o erótica. Te van sondeando visualmente, igual se van exponiendo un poquito, físicamente, los genitales. Las miradas son de una gran carga erótica (Ricardo).

Al ingresar al vagón, lo primero por hacer fue visualizar a quienes viajaban en su interior. La dinámica consistió en buscar e identificar una mirada compatible para sostenerse y acoplarse a ella, y luego hacer un giro hacia la entrepierna de manera seductora. Frecuentemente el cruce de miradas esporádicas daba la pauta a miradas más fijas y profundas, seguido de un apretón sobre el pantalón muy cerca de la entrepierna.

[...] aunque lleves prisa, sí te tomas dos o tres trenes para decidir dónde va el chavo más guapo o más bueno, más buenote, etcétera, o que te atraiga ¿no? Finalmente cada cual tenemos como nuestro gusto muy particular, pero yo creo que todo el mundo se toma y nos tomamos el tiempo como para discriminar con qué pasajeros sí nos vamos, y con qué pasajeros no. A lo mejor encuentras a uno que es suficiente razón para subirse, aunque todos los demás no valgan la pena para ti, pero te subes por ese en particular, que a lo mejor sí te hace caso y va súper disponible para ti, o sencillamente va totalmente negado a tener algún contacto visual o físico contigo (Ricardo).

Algunos hombres, con los ojos cerrados y como maniobra para sustraerse de la escena erótica y no "participar", simulaban no ver, complementando su estrategia con el uso del móvil, o con la lectura de cualquier libro o revista mientras otros eran testigos más fieles a las escenas colectivas de seducción y el filtreo entre el resto de los hombres, muy "pegaditos”, unos con otros.

El reflejo de los cuerpos sobre los vidrios de puertas y ventanas también fue una buena estrategia para el "metreo". Asimismo, y con cierta visibilidad de lo que acontecía en el reducido espacio del "último vagón", la distribución de los cuerpos durante el trayecto fue fundamental para el encuentro: cara a cara, espalda con espalda o de "ladito", todos los cuerpos se sincronizaron (armónicamente) con el movimiento del convoy.

En algunos hombres, "los bultos resaltados y apretados" (casi a reventar la cremallera del pantalón) no podían ocultarse, y si lo lograban, era con apoyo de una de sus manos o de cualquier objeto a su alcance (mochila, cuaderno o chamarra) sobre la parte en tensión. Una 
técnica que también ayudó a disimular los roces corporales y explorar la imaginación de sus protagonistas.

El contacto con las nalgas fue otro punto clave para saber si se aceptaba o no el cortejo erótico. Los cuerpos se aproximaron poco a poco, midiendo la tolerancia con el otro, hasta llegar al "arrimón", que solía ser más cercano. Ahí, el "tortazo" o la nalgada de uno hacia otro, facilitó el acceso a una práctica más cercana, erótica y sexual: el frotamiento entre las nalgas y el pene de los hombres viajeros.

[...] yo creo que primero es de lo que ves y ahí te reacomodas, buscas la manera de quedar cerca de esa persona, de tu objeto visual, ¿no? Y a partir de eso, igual te encuentras con unas súper nalgas o una súper verga, jasí bien choncha! no al verla, no por verla, sino al tocarla te das cuenta de las dimensiones. ¡Y dices wow! Aparte de las dimensiones, que esté bonita ¿no? O sea, buen cuello, cabeza grande, etcétera. O sea, primero buscas la manera de reacomodarte en frente de él, porque también cinco más están viendo lo mismo que tú (Aldo).

El contacto a través del desplazamiento de las manos por la estructura de metal, de tubos de acero del interior del vagón, fue otra práctica muy peculiar ligada al movimiento de la máquina del metro. En el acto cotidiano para asegurarse durante el trayecto del viaje, las manos solían encontrarse iniciando con un primer toque (a través del dedo meñique) que permitía el contacto piel con piel de las manos del otro. Si esto era tolerado, el contacto podía extenderse hasta un roce más amplio y frecuente con la piel llegando al enlace completo entre dedos, apretando con fuerza contra el tubo de metal.

En las horas pico, el "apretujón" de los cuerpos fue inevitable, los usuarios hombres ingresaron tratando de cubrir sus genitales y a la expectativa del "toqueteo" que podía ocurrir dentro. Otros solían entrar con las manos en el pecho, para anteponer una forma de límite y evitar el contacto cuerpo a cuerpo. Algunos otros, con manos abajo, podían dirigirse a buscar la entrepierna de un viajero, mientras colocaban la mirada en un punto contrario, disimulando o evitando el contacto visual cara a cara. Los cuerpos alrededor de la escena descrita se acoplaron para formar una "barrera" que incluía solo a los hombres deseados, el resto quedaba excluido y con la visibilidad nula para ver o ser parte de la escena homoerótica.

Hay como solidaridad, se hace como casita para que te explayes totalmente o se explayen contigo, y todos contigo se hacen en complicidad para protegerse, para que los demás viajeros comunes no se den cuenta (Raúl). 
En las horas pico, entre el ritmo del movimiento y la musicalidad del metro, los cuerpos quedaron unos detrás de otros, apretados y casi fusionados en un escenario donde la excitación del roce corporal fue la seducción que provocó la saturación del espacio durante la cotidianidad de la ciudad.

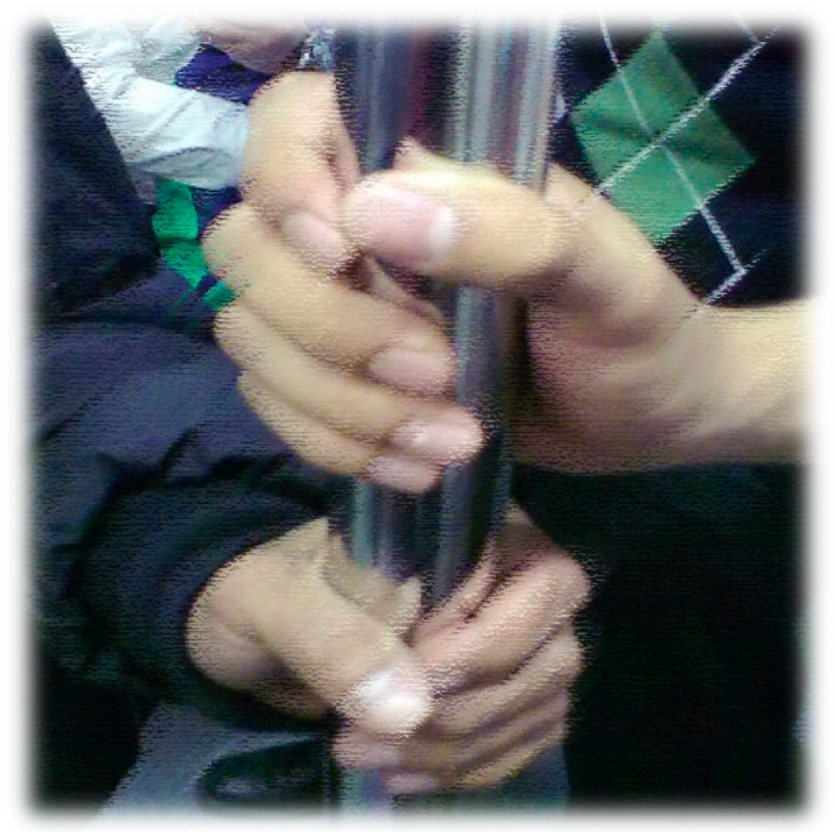

Foto 3. Llegando. Archivo personal, 2016.

\section{Reflexiones finales: el sentido rizomático}

En un transporte público como el metro, enmarcado por la espacialidad del territorio de la Ciudad de México y columna vertebral de la movilidad urbana de las grandes masas, queda claro que la experiencia humana trastoca el lugar para hacerlo espacio. Con base en el trabajo de campo realizado fue posible comprender el papel de la sexualidad, el cuerpo y la subjetividad en la configuración del espacio del "último vagón" del metro. Al transitar por andenes y pasillos, líneas de ruta y vagones, el espacio adquirió sentido subjetivo y significación social, pero, además, en el caso del "último vagón", la sexualidad emergió como catalizador de experiencias en torno a un espacio de frontera y transgresión.

Como reflexión y retomando a De Certeau (2007), se destacan la importancia y necesidad de un espacio social practicado para la diversidad sexual y la expresión de lo que se pueden llamar socialicorporalidades homoeróticas, articuladas a la capacidad humana de apropiación y 
significación de los espacios a través del cuerpo y suscritas por la vida cotidiana en la gran ciudad.

Las temporalidades que se reproducen en cada viaje se adaptan a los cambios vertiginosos de las relaciones humanas en tiempos globales. En este sentido, las prácticas homoeróticas entre hombres son productoras de realidades complejas que visibilizan imaginarios profundos en torno a la sexualidad, el cuerpo y el placer; pero también, con relación a creencias y mitos sobre el amor y las relaciones interpersonales entre hombres en la actualidad.

El "metreo" y el "ligue" (como prácticas "endógenas" del metro) ponen en evidencia los flujos de deseo, representados también en afectos, trazando rutas subjetivas y homoeróticas que orientan o guían a los usuarios-hombres hacía las más creativas formas de encuentro. Desde aquí es importante no olvidar que el caleidoscopio de los afectos en los hombres, desde su intensidad, complejidad y variabilidad son un elemento central en la estructuración de dichas prácticas pendiente de explorar.

Finalmente, no falta decir que, a través del tiempo, las prácticas homoeróticas en el "último vagón" del metro, dejan huellas que vislumbran sentidos, sostienen significados y proponen nuevas formas de interacción supeditadas a lógicas de sentido rizomático en constante devenir. 


\section{Referencias bibliográficas}

Augé, M. (2008). Los no lugares. Espacios del anonimato. Una antropología de la sobremodernidad, Barcelona: Gedisa.

Carrillo, H. (2002). La noche es joven. La sexualidad en México en la era del SIDA, Traducción Enrique Mercado, México: Océano.

Castoriadis, C. (2013). La institución imaginaria de la sociedad, Tusquets Fábula: México.

De Certeau, M. (2007). La invención de lo cotidiano. 1 Artes de hacer, $2^{\mathrm{a}}$ edición, México: Universidad Iberoamericana/ITESO.

Deleuze, G. (1989). “Capítulo 1. Los repliegues de la materia”. En El pliegue. Leibniz y el barroco, Barcelona: Paidós Studio,11-23.

Deleuze, G. y F. Guattari. (2000). Rizoma (Introducción), Traducción José Vázquez Pérez y Umbelina Larraceleta. $3^{\text {a }}$ edición, Valencia: Pretextos.

Fernández, A.M. (1993). La mujer de la ilusión. Pactos y contratos entre hombres y mujeres, México: Paidós.

Gallego, G. (2010). Demografía de lo otro: biografias sexuales y trayectorias de emparejamiento entre varones en la Ciudad de México. $1^{a}$ edición, México: El Colegio de México/Centro de Estudios Demográficos, Urbanos y Ambientales.

Laguarda, R. (2010). Ser gay en la ciudad de México: Lucha de representaciones y apropiación de una identidad, 1968-1982. $1^{\text {a }}$ edición. $1^{\text {a }}$ reimpresión, México: Instituto Mora/CIESAS.

Langarita, J. A. (2015). En tu árbol o en el mío: Una aproximación etnográfica a la práctica del sexo anónimo entre hombres, Barcelona: Bellaterra.

Monsiváis, C. (2009). Los rituales del caos, México: Era.

Monsiváis, C. (2010). Que se abra esa puerta. Crónicas y ensayos sobre la diversidad sexual. México: Paidós.

Morin, E. (2001). Introducción al pensamiento complejo. $1^{\mathrm{a}}$ edición. $5^{\mathrm{a}}$ reimpresión, Barcelona: Gedisa.

Muñiz, E. (2010). "Capítulo 1. Las prácticas corporales. De la instrumentalidad a la complejidad”. En Elsa Muñiz (coord.). Disciplinas y prácticas corporales. Una mirada a las sociedades contemporáneas, México: Anthropos/Universidad Autónoma Metropolitana. Unidad Azcapotzalco, 17-50.

Novo, S. (1998). La estatua de sal, México: Consejo Nacional para la Cultura y las Artes. Memorias Mexicanas. 
Novo, S. (1966 [2001]). Salvador Novo. Antología 1925-1965. 3 $3^{\text {a }}$ edición, México: Editorial Porrúa.

Núñez, G. (1994 [2000]). Sexo entre varones. Poder y resistencia en el campo sexual. 2a edición. $1^{\mathrm{a}}$ reimpresión, México: Programa Universitario de Estudios de Género, Universidad Nacional Autónoma de México.

Núñez, G. (2017). Abriendo Brecha. 25 años de estudios de género de los hombres y masculinidades en México (1990-2014), México: CIAD.

Vendrell, J. (2013). "La diversidad sexual y de género en el trabajo sexual de los hombres con otros hombres". En Turismo y sexo en México. Cuerpos masculinos en venta y experiencias homoeróticas. Una perspectiva multidisciplinaria, México: UNAM.

Weeks, J. (1998 [2000]). Sexualidad, México: Paidós/PUEG-UNAM. 